\title{
Macro-microscopic research in reideer (Rangifer tarandus) hoof suitable for efficient locomotion on complex grounds
}

\author{
Rui Zhang, Yu Qiao, Qiaoli Ji, Songsong Ma, Jianqiao Li \\ Key Laboratory of Bionic Engineering, Ministry of Education, \\ Jilin University, Nanguan District, Changchun, 130022, People's Republic of China \\ zhangrui@jlu.edu.cn
}

Received: November 25, 2016 Accepted: May 8, 2017

\begin{abstract}
Introduction: Reindeer are adapted to long distance migration. This species can cope with variations in substrate, especially in ice and snow environment. However, few detailed studies about reindeer hoof are available. Thus this article describes the results of studies on macro- and micro-structures of reindeer hoof. Material and Methods: The gross anatomy of the reindeer hooves was examined. Stereo microscope (SM) and a scanning electron microscope (SEM) were used to observe four key selected positions of reindeer hooves. Moreover, element contents of the three selected positions of reindeer hooves were analysed using the SEM equipped with energy dispersive spectroscope. Results: Hoof bone structures were similar to other artiodactyl animals. In the microscopic analysis, the surfaces of the ungula sphere and ungula sole presented irregular laminated structure. Ungula edge surfaces were smooth and ungula cusp surfaces had unique features. Aside from $\mathrm{C}, \mathrm{O}$, and $\mathrm{N}$, reindeer hooves contained such elements as $\mathrm{S}, \mathrm{Si}, \mathrm{Fe}, \mathrm{Al}$, and $\mathrm{Ca}$. The content of the elements in different parts varied. Ti was the particular element in the ungula sole, and ungula edge lacked $\mathrm{Mg}$ and $\mathrm{S}$ which other parts contained. Conclusion: The macroand micro-structures of the reindeer hooves showed high performance of skid and abrasion resistance. It is most probably essential to the long distance migration for the animals.
\end{abstract}

Keywords: reindeer, hoof, morphology, energy spectrum analysis, long distance migration.

\section{Introduction}

Reindeer (Rangifer tarandus) are migrant animals inhabiting the polar environment $(15,21)$. Semidomesticated reindeer, and especially wild forest reindeer, are well adapted to travel through deep and soft snow $(3,18)$. The hoof pillow of reindeer turns spongy in winter, which provides additional friction. Moreover, a contracting hoof pillow allows the edge of the reindeer hoof to come out, which contributes to increased speed while running on ice. Their sustained stability on icy ground is closely related to the characteristics of the whole leg and hoof. In the long evolutionary process, reindeer have become efficient long-distance migrants and are able to cope with variations in substrate, such as ice, snow, uneven forest floor, wetland, and flat grassland (14). According to Rankama and Ukkonen (22) and Flagstad and Røed (6), the evolutionary history of reindeer is still under debate. Reindeer populations have been found in the late Pleistocene through radiocarbon dating $(12,13)$. Due to the glacial periods and their ability to adapt to extreme weather conditions, reindeer migrated to the Northern Hemisphere (15). Since the feed distribution changed between seasons, the reindeer had to travel long distance to survive $(9,17,25)$. However, the semidomesticated populations of Eurasian mountain reindeer (R. t. tarandus) (28) only migrated at short distances. In summer season, due to insect harassment, reindeer also undertake short-distance migration (26, 27). Reindeer which migrate long distance between seasons (20) possess a range of anatomical adaptations typical of cursorial animals (8). Besides, reindeer demonstrate a high oxidative capacity of all fibers in their skeletal muscle, which may be linked to endurance activity (5).

In recent years, a number of anatomical experiments $(2,16)$ and research (1) on reindeer and other deer have been carried out. Lately, Giżejewska et al. (10) presented the trace element contents of red 
deer antlers. However, reindeer hoof anatomy has not been properly investigated. Thus, in this study, the macro- and micro-structures of reindeer hoof were analysed. The element contents were also determined to study the mechanism of the reindeer hoof with reference to their travelling in cold environment and long distance migration.

\section{Material and Methods}

Gross anatomy was used to analyse the internal structure of the hoof of reindeer. Moreover, imaging techniques were applied to observe the macro- and micro-structures of reindeer hoof. A stereo microscope (SM) and a scanning electron microscope (SEM) equipped with energy dispersive spectroscopy (EDS) were used according to a scrupulously prepared protocol. Images were compared in order to analyse the specimens' morphology, whereas EDS energy spectrum diagrams allowed to analyse the element contents in different regions of the reindeer hooves.

Test specimens. Four fore hooves and four hind hooves of two eight-year-old adult homebred reindeer were purchased from Ewenki group located in GenHe city. The reindeer were euthanised and the hooves were cut off. These hooves had not undergone any surgery.

Design and methods. The length and width of all hooves were measured. In addition, one fore hoof and one hind hoof were randomly selected dissection. Then, eight samples $(1 \mathrm{~cm} \times 1 \mathrm{~cm} \times 1 \mathrm{~cm})$ were taken from ungula cusp, ungula edge, ungula sole, and ungula sphere of one fore hoof and one hind hoof.

Gross anatomy. The samples were stored at $-20^{\circ} \mathrm{C}$ until required for dissection. They were split with hand saw, and the longitudinal and cross sections were examined.

Stereo microscopy. A SteREO Discovery V12 microscope (Carl Zeiss, Germany) was used. The image analysis system resolution was 10.4 megapixels, and the operating system was Vision Rel. 4.6 (Carl Zeiss, Germany). The test specimens were washed in water at $30^{\circ} \mathrm{C}$ for $4 \mathrm{~min}$ and dried with blotting paper. These samples were then examined under the microscope.

Scanning electron microscope (SEM) and energy dispersive spectroscopy (EDS). A 1000-B SEM (Philips XL30 ESEM-FEG, Germany) equipped with energy dispersive spectrometer was used at $6 \mathrm{~nm}$ resolution. The test specimens were fixed on a sample holder (carousel $9 \times 9 \mathrm{~mm}$ ) and dried in a lyophiliser. Finally, the samples were coated with gold-palladium in a sputtering device, put on the SEM stage as the scope operated at $5.0 \mathrm{Kv}$, examined, and photographed. In addition, EDS analysis provided chemical composition of a sample inside the SEM.

\section{Results}

The reindeer hoof was composed of capsule ungulates (epidermis) (Fig. 2b/5), corium ungulates (corium layer and subcutaneous tissue) (Figs 2b/6, 7, 8), distal phalanx (Fig. 2a/1), middle phalanx (Fig. 2a/2), distal sesamoid bone (Fig. 2a/3), and proximal phalanx (Fig. 2a/4). Capsuled ungulates wrapped distal phalanx bone (Fig. 2a/4) and distal sesamoid bone (Fig. 2a/3). The anatomical structures of the fore hoof and the hind hoof were similar. The capsuled ungulate was composed of ungula limbus (Fig. 1a/1), ungula wall (Fig. 1a/2), ungula coronal (Fig. 1a/3), ungula cusp (Fig. 1b/4), ungula sole (Fig. 1b/5), ungula edge (Fig. 1b/6), and ungula sphere (Fig. 1b/7). The length (Fig. 1b/L) and width (Fig. 1b/W) of all hooves were measured, and the results are shown in Table 1 . The mean length and width of the fore hooves were $87.0 \mathrm{~mm}$ and $38.1 \mathrm{~mm}$ and the hind hooves were $74.6 \mathrm{~mm}$ and $31.8 \mathrm{~mm}$, respectively.

Ungula limbus epidermis (Fig. 1a/1) was the junction of hairy skin and glabrous skin, and its colour was white. Many funnel-shaped cutin tubula openings were distributed on the internal surface of epidermis. Ungula coronal epidermis was distributed below the capsuled ungulate epidermis and was black in colour. Funnel-shaped cutin tubular openings were also distributed on corium ungulate epidermis. Abundant adipose tissue was observed under the subcutaneous tissue layer of ungula coronal. Ungula wall was the hardest part of ungula capsula epidermis and below ungula cornal epidermis. The bottom of reindeer hoof was ungula sole.

The ungula sphere was surrounded by ungula limbus, ungula coronal, ungula wall, and ungula sole. It had round pad structure, and its texture was soft. Plentiful adipose tissue was distributed on subcutaneous tissue layer of ungula sphere (Figs 2b/6, 7,8).

Fig. 3 shows the surfaces of ungula sphere (Fig. 3/a), ungula sole (Fig. 3/b), ungula edge (Fig. 3/c), and ungula cusp (Fig. 3/d). Under SM observation, the surface of ungula sphere was rough and presented a rib-shaped micro-convex structure. There were little differences between ungula sole and ungula edge surfaces. In addition, ungula cusp surface exhibited cracks.

Table 1. Measurements of reindeer hoof bottom

\begin{tabular}{|c|c|c|c|c|c|c|c|c|c|c|}
\hline \multirow[b]{2}{*}{ Length (mm) } & \multicolumn{4}{|c|}{ Fore hoof } & \multirow{2}{*}{$\begin{array}{c}\text { Means } \pm \text { S.D } \\
87.0 \pm 1.6\end{array}$} & \multicolumn{4}{|c|}{ Hind hoof } & \multirow{2}{*}{$\begin{array}{c}\text { Means } \pm \text { S.D } \\
74.6 \pm 1.0\end{array}$} \\
\hline & 88.2 & 88.5 & 85.1 & 86.2 & & 75.6 & 75.2 & 73.5 & 74.0 & \\
\hline Width (mm) & 39.0 & 39.4 & 37.3 & 36.8 & $38.1 \pm 1.3$ & 32.6 & 33.0 & 30.5 & 31.2 & $31.8 \pm 1.2$ \\
\hline
\end{tabular}



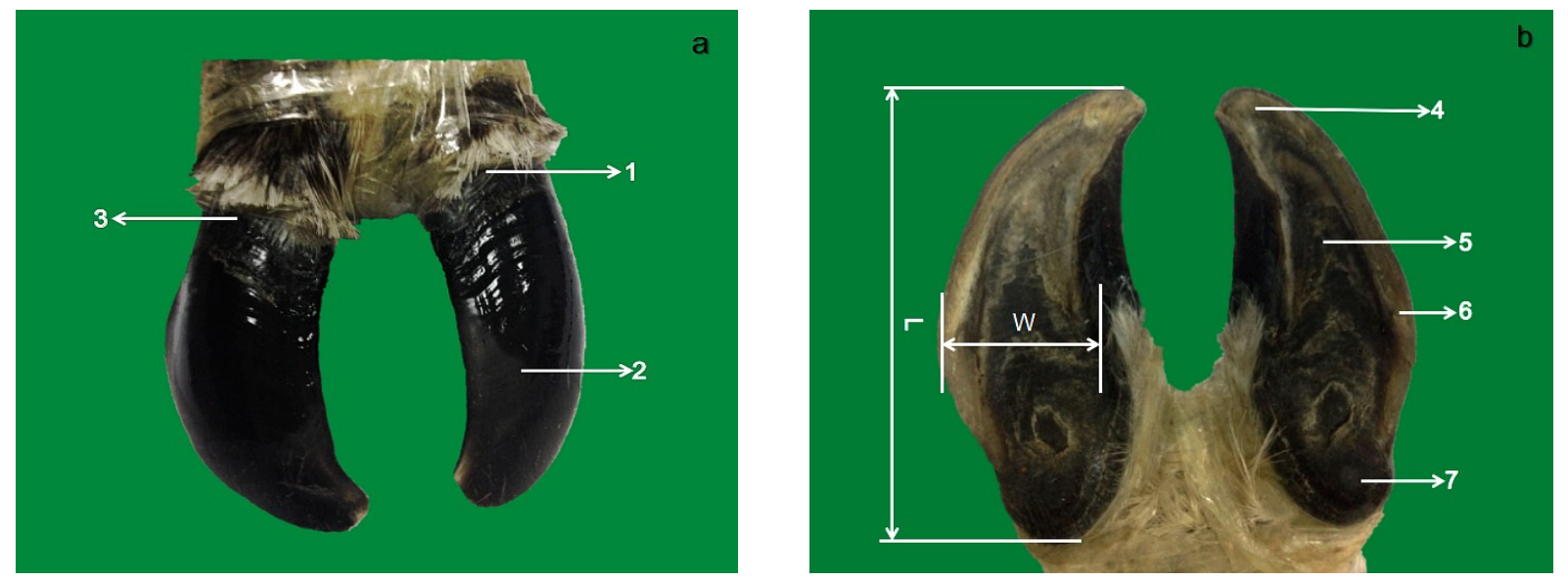

Fig. 1. Dorsal aspect (a) and bottom aspect (b) of reindeer hoof. 1 - ungula limbus; 2 - ungula wall; 3 - ungula coronal; W - hoof width; $\mathrm{L}$ - hoof length; 4 - ungula cusp ; 5 - ungula sole; 6 - ungula edge ; 7 - ungula sphere
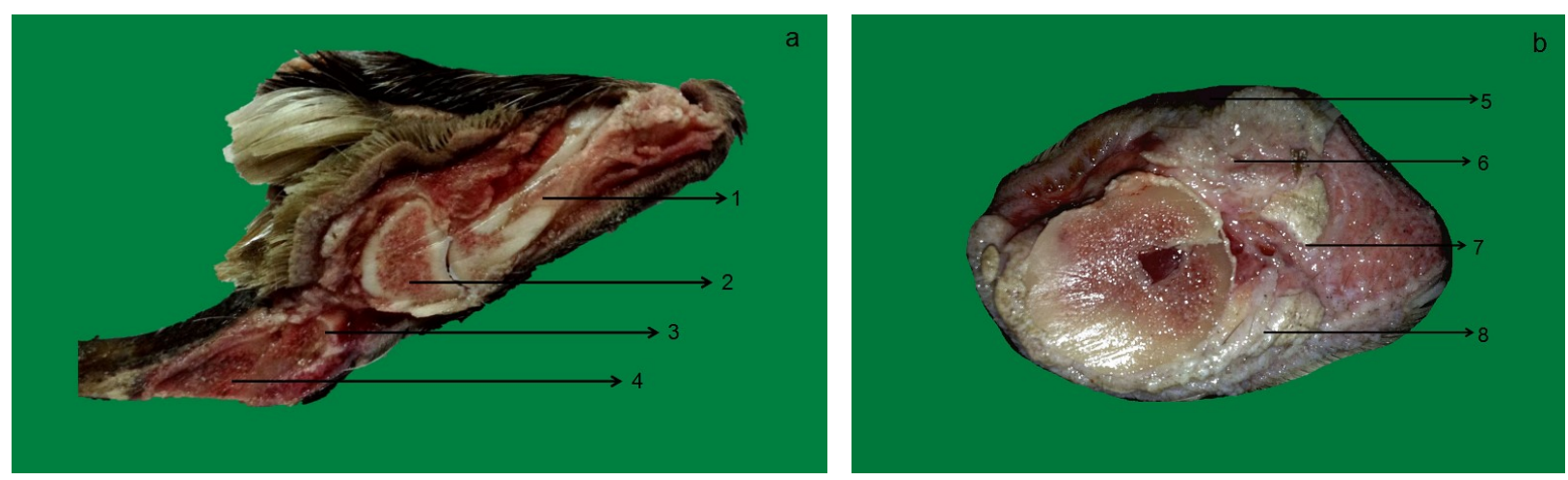

Fig. 2. Longitudinal section (a) and transverse section (b) of reindeer hoof. 1 - distal phalanx; 2 - middle phalanx; 3 - distal sesamoid bone; 4 - proximal phalanx; 5 - ungula capsula; 6 -abaxial fat pads; 7 - middle fat pads; 8 -axial fat pads
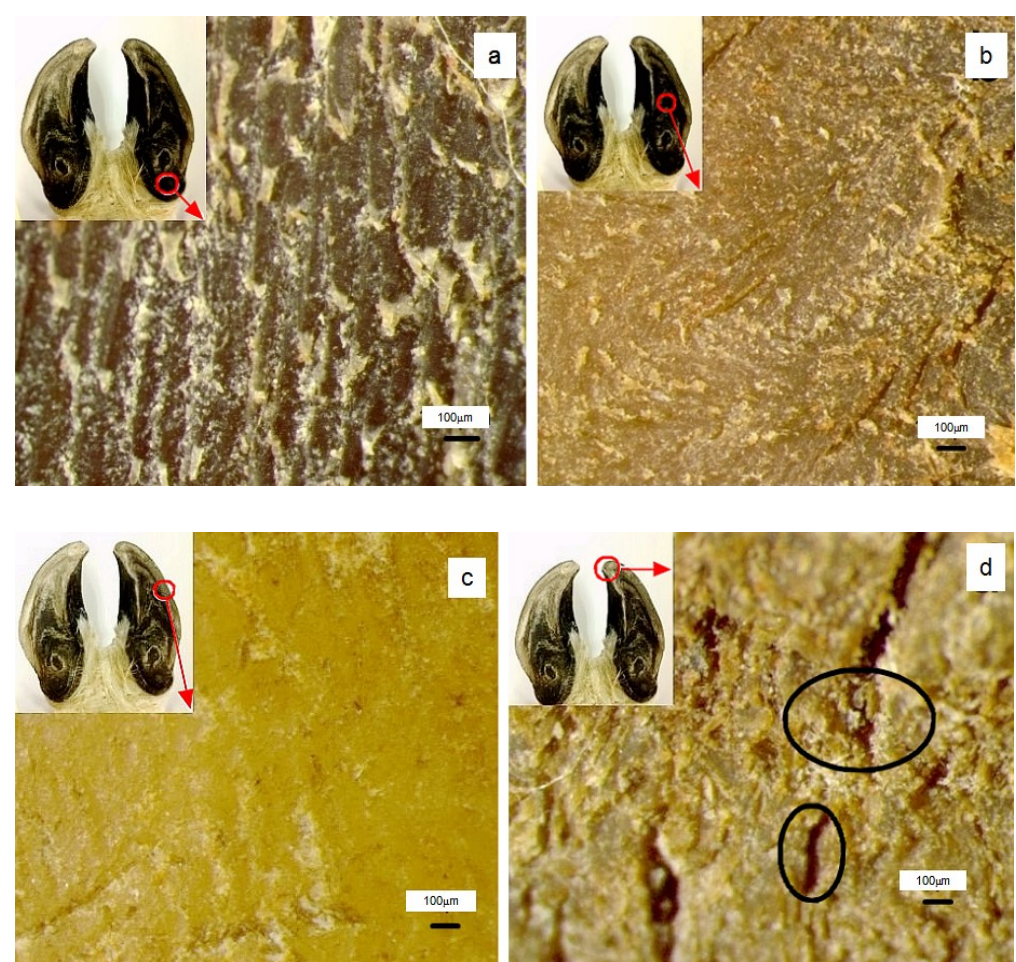

Fig. 3. SM photograph $(20 \times)$. a - ungula sphere; b - ungula sole; c - ungula edge; d - ungula cusp 
Using SEM, the micro-structure of four features was obtained. The ungula sphere surface was composed of irregular sheet laminated structures. Figs 4/a, a' and $5 / a, a^{\prime}$ illustrate that the surface of ungula sphere of the fore hoof was rougher than the hind hoof in the same multiples.

In a larger magnification, the ungula sole surface presented a cascade structure (Figs $4 / \mathrm{b}, \mathrm{b}^{\prime}$ and $5 / \mathrm{b}, \mathrm{b}^{\prime}$ ) with a much denser distribution than in ungula sphere. Because this part does not come in direct contact with the ground while the reindeer walks, the differences in micro-structure of ungula sole of fore and hind hoof are insignificant.

Under SEM, micro-structure of ungula edge surface was flat (Fig. 4/c, $c^{\prime}$ ). This part touches the ground frequently, and has smooth sharp edges, which help the reindeer to catch the ice and solidify the snow, preventing it from falling. There were no significant differences between the fore hoof and the hind hoof under SEM $(200 \times)$. However, the ungula edge surface of the hind hoof was smoother (Fig. 5/c), while some stripy structures were visible (Fig. 5/c') under SEM (2000×).
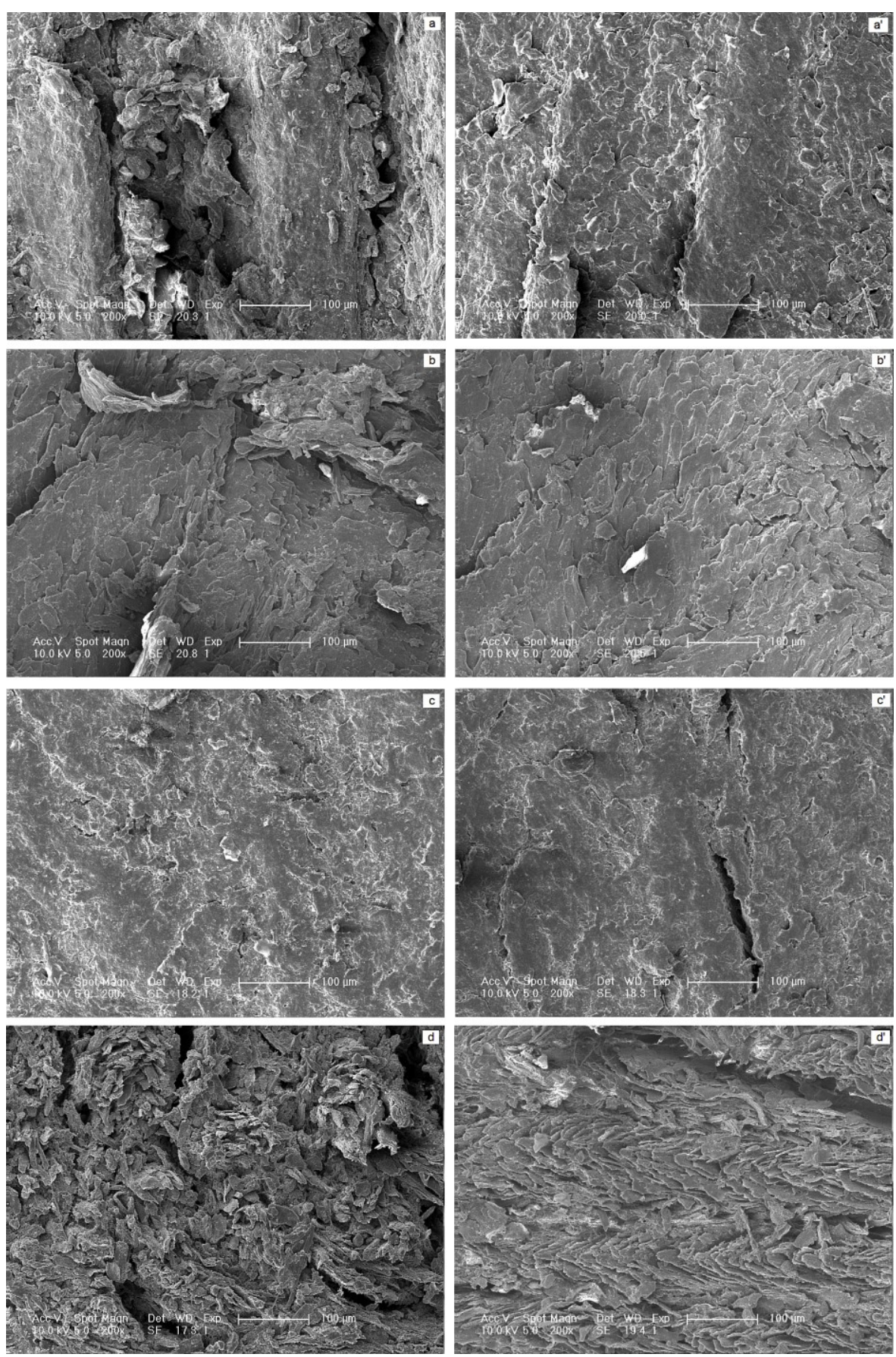

Fig. 4. SEM photograph $(200 \times)$. $a-$ ungula sphere of fore hoof; $b-$ ungula sole of fore hoof; $c-$ ungula edge of fore hoof; $\mathrm{d}$ - ungula cusp of fore hoof; $\mathrm{a}^{\prime}$ - ungula sphere of hind hoof; $\mathrm{b}^{\prime}$ - ungula sole of hind hoof; $\mathrm{c}^{\prime}$ - ungula edge of hind hoof; $\mathrm{d}^{\prime}-$ ungula cusp of hind hoof 
An important difference in ungula cusp was observed under SM and SEM. The irregular, dense, scale structures of ungula cusp surface of the hind hoof were different from the sheet laminated structures of other parts (Fig. 4/d, Fig. 5/d). However, the ungula cusp surface of the fore hoof presented an irregular structure (Fig. 4/d', Fig. 5/d').

Using EDS, the chemical element contents of the ungula sphere, ungula sole, and ungula edge were established (Table 2). Carbon, oxygen, and nitrogen are undoubtedly the main elements (ungula sphere: $\mathrm{C}-43.16 \%, \mathrm{O}-41.38 \%, \mathrm{~N}-7.15 \%$; ungula sole: $\mathrm{C}-42.9 \%, \mathrm{O}-39.31 \%, \mathrm{~N}-4.86 \%$; ungula edge: $\mathrm{C}-44.54 \%, \mathrm{O}-40.53 \%, \mathrm{~N}-8.23 \%$ ). The average contents of elements in different parts of the hoof of the reindeer are shown in Table 2.
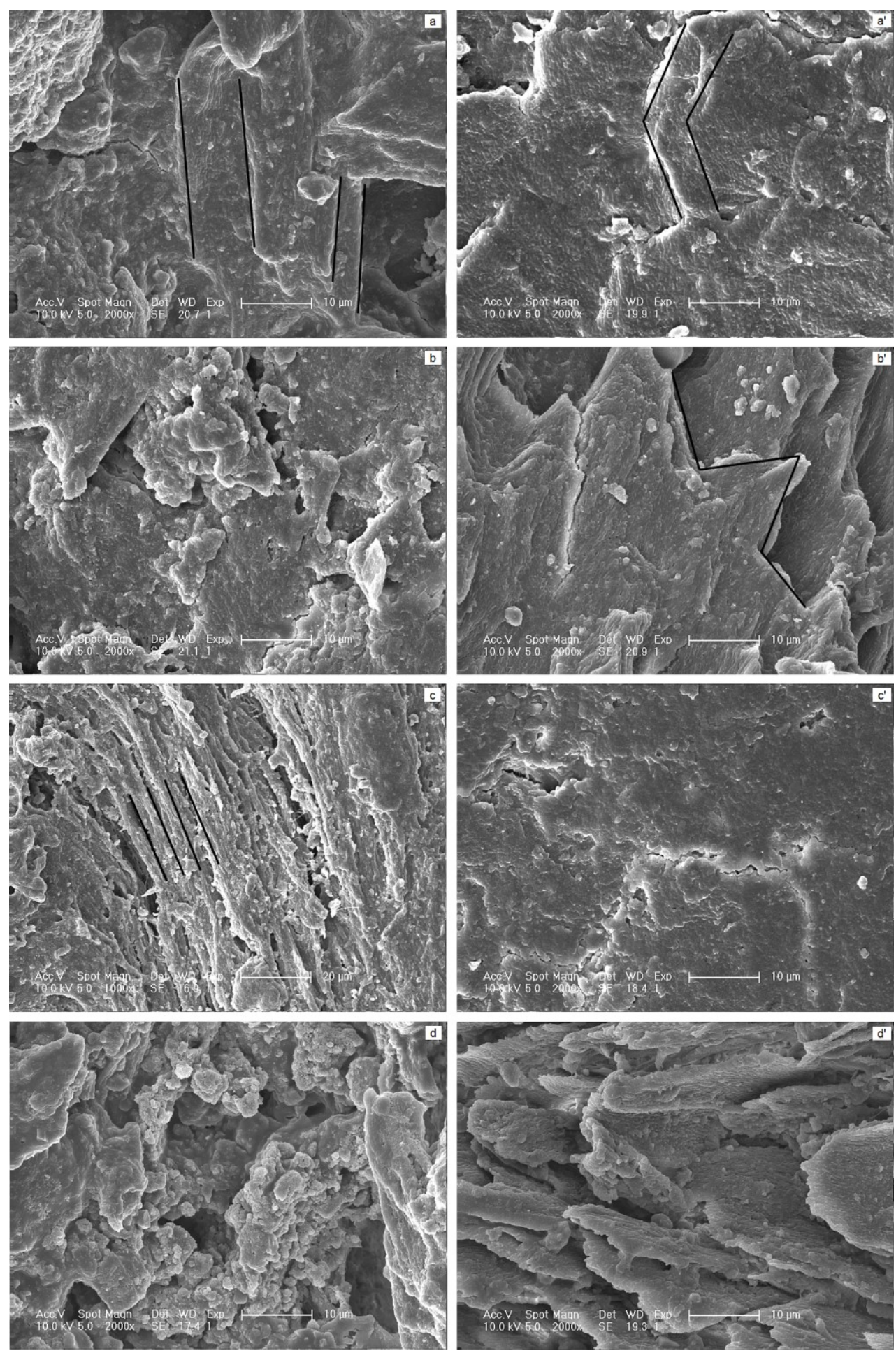

Fig. 5. SEM photograph $(2000 \times)$. a - ungula sphere of fore hoof; b - ungula sole of fore hoof; c - ungula edge of fore hoof; $d$ - ungula cusp of fore hoof; $a^{\prime}$ - ungula sphere of hind hoof; $b^{\prime}-$ ungula sole of hind hoof; $c^{\prime}-$ ungula edge of hind hoof; $\mathrm{d}^{\prime}$ - ungula cusp of hind hoof 
Table 2. Contents of elements in different parts of reindeer hoof $(\%)$

\begin{tabular}{lllllllllllllll}
\hline Element & $\mathrm{C}$ & $\mathrm{N}$ & $\mathrm{O}$ & $\mathrm{Ca}$ & $\mathrm{Si}$ & $\mathrm{Al}$ & $\mathrm{S}$ & $\mathrm{Fe}$ & $\mathrm{Cl}$ & $\mathrm{Mg}$ & $\mathrm{K}$ & $\mathrm{Ti}$ \\
\hline $\begin{array}{l}\text { Ungula } \\
\text { sphere }\end{array}$ & 43.16 & 7.15 & 41.38 & 3.42 & 1.72 & 1.41 & 0.52 & 0.4 & 0.8 & 0.21 & 0.16 & - \\
\hline $\begin{array}{l}\text { Ungula } \\
\text { sole }\end{array}$ & 42.9 & 4.86 & 39.31 & 5.02 & 4.16 & 1.44 & 0.49 & 0.57 & 0.38 & 0.26 & 0.33 & 0.34 \\
\hline $\begin{array}{l}\text { Ungula } \\
\text { edge }\end{array}$ & 44.54 & 8.23 & 40.53 & 2.43 & 2.8 & 1.25 & $-{ }^{*}$ & 0.6 & 0.28 & $-^{*}$ & 0.24 & $-{ }^{*}$ \\
\hline
\end{tabular}

*: - no element

Elements contained in reindeer hoof included calcium, silicon, aluminum, sulphur, chlorine, kalium, iron, magnesium and titanium. Calcium, silicon, and aluminum were the main elements of all three selected parts (total contents of $\mathrm{Ca}, \mathrm{Si}$, and $\mathrm{Al}$ were $6.55 \% \sim 10.59 \%)$. The ungula sole calcium and silicon contents $(5.02 \%$ and $4.16 \%$, respectively) were higher than others (ungula sphere: $3.42 \%$ and $1.72 \%$; ungula edge: $2.43 \%$ and $2.80 \%$, respectively).

\section{Discussion}

Qualitatively, the musculoskeletal anatomy of the reindeer hooves followed the standard ungulate pattern. Due to the lack of comparative data, quantitative variation within this group or other artiodactyls could not be investigated. The fatty structure of ungula sphere resembled a bumper, and it could decrease the peak pressures exerted by the ground. When reindeer walk, the heel touches the ground and gradually becomes flat; the weight is transferred to the ungula cusp, and capsula ungulae expands to the sides. Thus, the footpads absorb more pressure, which facilitates long distance migration and protects the hoof against damage.

The rib-shaped micro-convex and irregular lamellar structure were observed on ungula sphere surface. This structure may be associated with wear resistance and buffer performance (4, 19). Additionally, the micro-structure of ungula sole surfaces demonstrated an irregular lamellar structure similar to ungula sphere under SEM. The different structures on ungula edge between the fore hoof and the hind hoof visible under SEM in large magnification may result from the unique interaction between the fore/hind hoof and the ground. The ungula cusp was the most seriously abraded area out of all four sites and many cracks were visible under SM. This angled part may possibly contribute to force concentration when reindeer walk and run on icy ground. Besides, the micro-structure of this part was unique compared with others, its irregular scale structures were densely packed under SEM, which resulted in good abrasion resistance and sufficient hardness of the reindeer hoof. In magnification of up to $10,000 \times$, every micro-structure of the four parts was composed of circular protrusions. It may contribute to destruction of the water film on ice and enhance the anti-skid performance. Importantly, the surface micro-structures of ungula sphere, ungula sole, ungula edge, and ungula cusp were different in fore and hind hooves. It may be related to the centre of mass that is close to the forelimb in most cursorial quadrupeds with the exception of primates $(9,11,14$, 22); as a result, the application of force between the fore hoof ungula sphere and the hind hoof is different. These features help reindeer to perform long distance migration.

The results of the chemical element content analysis showed the differences among different parts of reindeer hoof. The calcium and silicon contents of ungula sole were higher than others. Magnesium and sulphur were not detected in the ungula edge, and calcium content was the lowest in the three samples. Besides, titanium was a peculiar element of the ungula sole. Different chemical elements meant different compounds, and different surfaces with different wearresistance were composed of different elements (24). These elements may enhance abrasive resistance and anti-skid performance.

In this study, gross anatomy and imaging techniques were applied to observe the macroscopic and microscopic structures of the reindeer hooves. We suppose that these results could be potentially used to design wear-resistant and anti-skid materials. Furthermore, it needs to be mentioned that high density bristles form a close brush around the hooves and these bristles contacted with ground directly while reindeer walk on snow and ice. It increases the contact area with the ground, which reduces the dynamic pressure of reindeer hoof. These characteristics may enhance reindeer capacity for long distance migration. Therefore, further research on bristles will be conducted in the future.

Conflict of Interests Statement: The authors declare that there is no conflict of interests regarding the publication of this article.

Financial Disclosure Statement: The research has been funded by the National Natural Science Foundation of China (No.51675221, 51275199).

Statement of Animal Rights: All procedures performed in the study involving animals were in 
accordance with the ethical standards of the institution at which the studies were conducted.

\section{References}

1. Alex M.: Basic veterinary management of reindeer. In Practice 2014, 36, 495-500.

2. Brage B.H., Ronny A.: Kelp and seaweed feeding by HighArctic wild reindeer under extreme winter conditions. Polar Res 2012, 31, 1-6.

3. Currey J.D.: The design of mineralised hard tissues for their mechanical functions. J Exp Biol 1999, 202, 3285-3294.

4. Essén-Gustavsson B., Rehbinder C.: Skeletal muscle characteristics of reindeer (Rangifer tarandus L). Comp Biochem Phys A 1985, 82, 675-679.

5. Emes B., Larson S.G., Stern J.T., Jungers W.L., Biknevicius A.R., Schmitt D.: The kinetics of primate quadrupedalism-hindlimb drive reconsidered. J Hum Evol 1994, 26, 353-374.

6. Flagstad Ø., Røed K.H.: Refugial origins of reindeer (Rangifer tarandus $L$ ) inferred from mitochondrial DNA sequences. Evolution 2003, 57, 658-670.

7. Fancy S.G., Pank L.F., Whitten K.R., Regelin W.L.: Seasonal movements of caribou in Arctic Alaska as determined by satellite. Can J Zool 1989, 67, 644-650.

8. Ferguson S.H., Elkie P.C.: Seasonal movement patterns of woodland caribou (Rangifer tarandus caribou). J Zool 2003, 262, 125-134.

9. Franz T., Demes B., Carlson K.: Gait mechanics of lemurid primates on terrestrial and arboreal substrates. J Hum Evol 2005, 48, 199-217.

10. Giżejewska A., Nawrocka A., Szkoda J., Żmudzki J., Jaroszewski J., Giżejewski Z.: Variations of selected trace element contents in two layers of red deer antlers. J Vet Res 2016, 60, 467-471.

11. Guthrie R.D.: Frozen fauna of the mammoth steppe, the story of Blue Babe. J Vertebr Paleontol 1990, 10, 400-401.

12. Houszka M., Piekarska J., Podkowik M., Gorczykowski M., Bania J.: Morphology and molecular study of Fascioloides magna - a growing threat to cervids (Cervidae) in Poland. J Vet Res 2016, 60, 435-439.

13. Kimura T., Okada M., Ishida H.: Kinesiological characteristics of primate walking, its significance in human walking. In:
Environment behavior and morphology, dynamic interactions in primates. edited by Gustav Fischer, New York, 1979, pp. 297-311.

14. Katy W., Peter G.T., Karl-Arne S., Jonathan R.C., William I.S.: The musculoskeletal anatomy of the reindeer (Rangifer tarandus): fore-and hindlimb. Polar Biol 2011, 34, 1571-1578.

15. Lie R.W.: Animal bones from the Late Weichselian in Norway Fauna. Norvegica Serie 1986, A7, 41-46.

16. Mårell A., Ball J.P., Hofgaard A.: Foraging and movement paths of female reindeer, insights from fractal analysis correlated random walks and Levy Xights. Can J Zool 2002, 80, 854-865.

17. Mauri N.: Hoof and hoof loads for reindeer (Rangifer tarandu). Rangifer 1990, 10, 249-254.

18. Nakayama M., Tagashira H., Konishi S., Ogura K.: A direct electrochemical route to construct a polymer/manganese oxide layered structure. Inorg Chem 2004, 43, 8215-8217.

19. Nicholson K.L., Arthur S.M., Horne J.S., Garton E.O., Del Vecchio P.A.: Modeling caribou movements: seasonal ranges and migration routes of the Central Arctic Herd. PLoS One 2016, 11, 1-20.

20. Nowak R.M.: Walker's mammals of the world. John Hopkins University Press, Baltimore and London, 1999, pp. 1936-1937.

21. Payne R.C., Hutchinson J.R., Robilliard J.J., Smith N.C., Wilson A.M.: Functional specialisation of pelvic limb anatomy in horses (Equus callabus). J Anat 2005, 206, 557-574.

22. Rankama T., Ukkonen P.: On the early history of the wild reindeer (Rangifer tarandus L) in Finland. Boreas 2001, 30, $131-147$.

23. Rui Z., Songsong M., Xiujuan L., Gang L., Shuliang X., Jianqiao L.: Macroscopic and microscopic study of integuments on ostrich (Struthio camelus) hoof. J Vet Res 2016, 60, 219-226.

24. Skogland T.: Comparative summer feeding strategies of Arctic and Alpine Rangifer. J Anim Ecol 1980, 49, 81-98.

25. Skogland T.: Wild reindeer foraging-niche organisation. Holarctic Ecol 1984, 7, 345-379.

26. Skarin A., Danell Ö., Bergström R., Moen J.: Insect avoidance may override human disturbances in reindeer habitat selection. Rangifer, 2004, 24, 95-103.

27. Tyler N.J.C., Oritsland N.A.: Why don't Svalbard reindeer migrate? Holarctic Ecol 1989, 12, 369-376.

28. Vistnes I.I., Nellemann C., Jordhøy P., Støen O.: Summer distribution of wild reindeer in relation to human activity and insect stress. Polar Biol 2008, 31, 1307-1317. 